\title{
Semi-quantitative grading and extended semi-quantitative grading for osteoporotic vertebral deformity: a radiographic image database for education and calibration
}

\author{
Yì Xiáng J. Wáng ${ }^{1}$, Daniele Diacinti ${ }^{2}$, Wei Yu ${ }^{3}$, Xiao-Guang Cheng ${ }^{4}$, Marcello H. Nogueira-Barbosa ${ }^{5}$, \\ Nazmi Che-Nordin ${ }^{1}$, Giuseppe Guglielmi ${ }^{6}$, Fernando Ruiz Santiago ${ }^{7}$ \\ ${ }^{1}$ Department of Imaging and Interventional Radiology, the Chinese University of Hong Kong, Prince of Wales Hospital, Shatin, New Territories, \\ Hong Kong, China; ${ }^{2}$ Department of Radiological Sciences, Oncology and Anatomo-Pathology, University Sapienza, Rome, Italy; ${ }^{3}$ Department of \\ Radiology, Peking Union Medical College Hospital, Beijing 100005, China; ${ }^{4}$ Department of Radiology, Beijing Jishuitan Hospital, Beijing 100035, \\ China; ${ }^{5}$ Department of Radiology, Ribeirão Preto Medical School, University of São Paulo, Ribeirão Preto, Brazil; ${ }^{6}$ Department of Clinical and \\ Experimental Medicine, University of Foggia, Foggia, Italy; ${ }^{7}$ Department of Radiology, Hospital of Traumatology, Carretera de Jaen SN, Granada, \\ Spain \\ Contributions: (I) Conception and design: YXJ Wáng; (II) Administrative support: YXJ Wáng, N Che-Nordin; (III) Provision of study materials \\ or patients: YXJ Wáng; (IV) Collection and assembly of data: YXJ Wáng, N Che-Nordin; (V) Data analysis and interpretation: All authors; (VI) \\ Manuscript writing: All authors; (VII) Final approval of manuscript: All authors. \\ Correspondence to: Dr. Yì Xiáng J. Wáng. Department of Imaging and Interventional Radiology, Chinese University of Hong Kong, Prince of Wales \\ Hospital, Shatin, New Territories, Hong Kong, China. Email: yixiang_wang@cuhk.edu.hk.
}

\begin{abstract}
The Genant's semi-quantitative (GSQ) criteria is currently the most used approach in epidemiology studies and clinical trials for osteoporotic vertebral deformity (OVD) evaluation with radiograph. The qualitative diagnosis with radiological knowledge helps to minimize false positive readings. However, unless there is a face-to-face training with experienced readers, it can be difficult to apply GSQ criteria by only reading the text description of Genant et al. (in 1993), even for a musculoskeletal radiologist. We propose an expanded semi-quantitative (eSQ) OVD classification with the following features: (I) GSQ grade- 0.5 is noted as minimal grade (eSQ grade-1) for OVDs with height loss $<20 \%$; (II) GSQ mild grade (grade-1) is the same as eSQ mild grade (grade-2); (III) GSQ moderate grade (grade-2) is subdivided into eSQ grade-3 (moderate, >25\%-1/3 height loss) and eSQ grade-4 (moderately-severe, >1/3-40\% height loss); (IV) GSQ severe grade is subdivided into eSQ grade-5 (severe, >40\%-2/3 height loss) and eSQ grade-6 (collapsed, with $>2 / 3$ height loss). We advocate to estimate vertebral height loss with adjacent vertebral heights as the reference (rather than using individual vertebra's posterior height as the reference). This article presents radiographs of 36 cases with OVD, together with gradings using GSQ criteria and eSQ criteria. The examples in this article can serve as teaching material or calibration database for readers who will use GSQ criteria or eSQ criteria. Our approach for quantitative measurement is explained graphically.
\end{abstract}

Keywords: Osteoporosis; osteoporotic vertebral deformity (OVD); osteoporotic vertebral fracture; spine; grading

Submitted Jan 29, 2020. Accepted for publication Feb 28, 2020.

doi: $10.21037 /$ atm.2020.02.23

View this article at: http://dx.doi.org/10.21037/atm.2020.02.23

(C) Annals of Translational Medicine. All rights reserved. 
The Genant's semi-quantitative (GSQ) criteria is currently the most used approach in epidemiology studies and clinical trials for osteoporotic vertebral deformity (OVD, also referred to as osteoporotic vertebral fracture in some literatures) evaluation with radiograph (1-3). The qualitative diagnosis with radiological knowledge helps to minimize false positive readings due to vertebral physiological wedging, degenerative wedging, and other congenital anomalies. Also, importantly, radiological evaluation can detect subtle changes that may be clinically important, such as endplate and/or cortex fracture (ECF) (4). However, unless there is a face-to-face training with experienced readers, it can be difficult to apply GSQ criteria by only reading the text description of Genant et al, even for a musculoskeletal radiologist (5-10). There are two main difficulties. The first difficulty is to decide whether a mild OVD exists for a vertebra, or it is only a physiological wedging or degenerative wedging. The second difficulty is the precise grading $(8,10)$. The agreement among readers for OVD GSQ grading can be poor; this point has been well discussed in literature (5-8). These difficulties may not be so an issue for clinical practice; but can cause problems for epidemiological studies or drug trial follow-ups, and particularly for cross-center results comparison. One more point concerns GSQ grade- 0.5 , which refers to OVDs with less than $20 \%$ height loss. However, while GSQ grade- 0.5 OVDs are common, it is less reported and discussed in literature. Actually, many GSQ grade-0.5 OVDs might have been assigned as SQ grade-1 in literature. The examples can be seen in both Genant et al.'s 1993 original paper [Figure 2A of Genant et al. (1), mild OVD with less than 20\% height loss] and international osteoporosis foundation's teaching materials (slide 14 at https://www.iofbonehealth.org/whatwe-do/training-and-education/educational-slide-its/vertebralfracture-teaching-program, accessed on December 17, 2019).

Based on our experience in epidemiology studies and previous work (10-14), we propose an expanded semiquantitative (eSQ) OVD classification (Table 1) with the following features: (I) GSQ grade-0.5 is noted as minimal grade (eSQ grade-1) for OVDs with height loss $<20 \%$. Note, the clinical relevance of these OVDs is not necessarily linearly related to the extent of height loss. eSQ grade-1 OVD can be important for some cases seen in clinical practice, particularly when there is associated ECF (4,11,15-19); (II) GSQ mild grade (grade-1) is the same as eSQ mild grade (grade-2); (III) GSQ moderate grade (grade-2) is subdivided into eSQ grade-3 (moderate, $>25 \%-$ $1 / 3$ height loss) and eSQ grade-4 (moderately-severe, $>1 / 3$ $40 \%$ height loss). OVDs with $>1 / 3$ height loss are always associated with positive ECF sign radiographically (this is the reason for such a subdivision) $(11,12,14)$. The importance of recognizing ECF has been well discussed $(8,11,12,15,16)$, and how to recognize ECF has also been explained (4,20-23); (IV) GSQ severe grade is subdivided into eSQ grade-5 (severe, $>40 \%-2 / 3$ height loss) and eSQ grade-6 (collapsed, with $>2 / 3$ height loss). Such a subdivision is useful in assessing VD progression, e.g., an OVD with $45 \%$ height loss progressed to $75 \%$ height loss can be noted as a progression from eSQ grade-5 to eSQ grade-6; while such a message cannot be communicated with original GSQ criteria. Note this eSQ grading criteria can also be flexibly modified to suit individual study's need. For example, the subdivision between $25 \%$ and $40 \%$ vertebral height loss (>25\%-1/3 for eSQ grade-3 and 1/3-40\% for eSQ grade-4) can be removed, so that GSQ's moderate grade will be the same as the eSQ's moderate grade; or all OVD with $>1 / 3$ vertebral height loss (thus always associated with ECF) could be graded as 'severe' $(10,14)$. This eSQ is intended primarily for research purpose. For daily practice, a simpler classification would suffice (10).

A qualitive diagnosis of OVD should be made prior to estimation of the extent vertebral height loss; and for

Table 1 Vertebral height loss criteria for GSQ grading and eSQ grading*

\begin{tabular}{|c|c|c|c|c|c|c|}
\hline Grading & \multicolumn{6}{|c|}{ Extent of vertebral height loss } \\
\hline Genant SQ & Grade- 0.5 & Grade-1 & \multicolumn{2}{|c|}{ Grade-2 } & \multicolumn{2}{|c|}{ Grade-3 } \\
\hline Genant SQ & - & Mild & \multicolumn{2}{|c|}{ Moderate } & \multicolumn{2}{|c|}{ Severe } \\
\hline Extended SQ & Grade-1 & Grade-2 & Grade-3 & Grade-4 & Grade-5 & Grade- 6 \\
\hline
\end{tabular}

${ }^{*}$, vertebrae with normal radiographical morphology is noted as grade- 0 . 

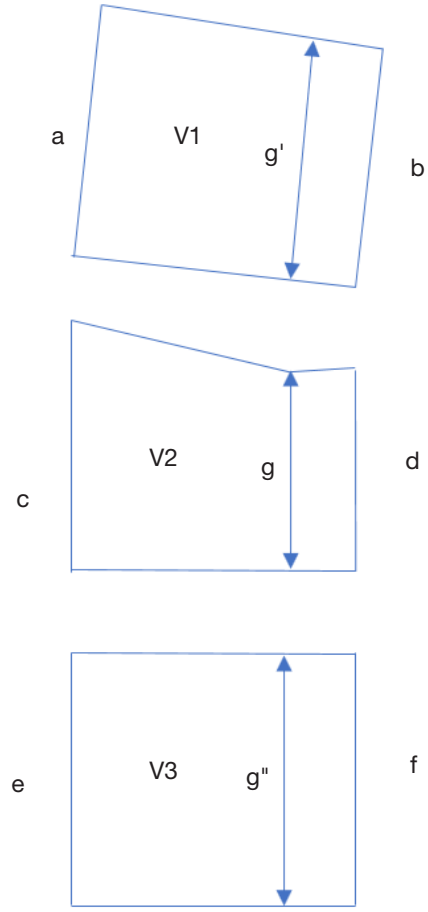

Figure 1 Estimation of the height loss of a vertebra. If vertebra V2 is qualitatively evaluated to have deformity, while vertebra $\mathrm{V} 1$ and vertebra V3 are without deformity, and if a, c, e are of similar height, then the expected $d=(b+f) \times 0.5$. If $d$ is shortened while measured more (higher) than $g$, then the expected $g$ (for V2 without deformity) can be estimated as $\left(g^{\prime}+g^{\prime \prime}\right) \times 0.5$, thus the percentage height loss of V2 is $1-g /\left[\left(g^{\prime}+g^{\prime \prime}\right) \times 0.5\right]$.

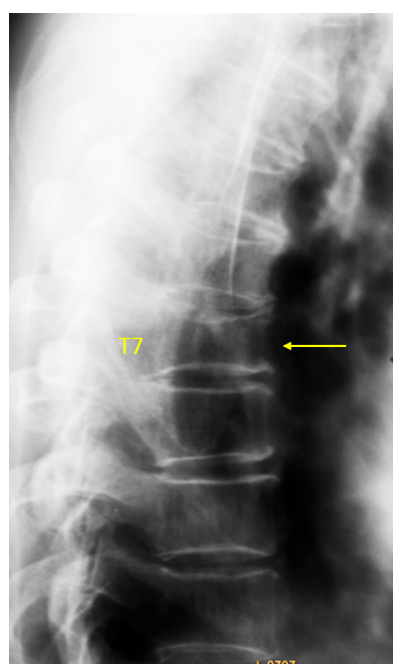

Figure 2 Vertebra T7 OVD, estimated 25-33\% height loss (GSQ grade-2, eSQ grading: moderate). diagnosis of OVD, a lack of morphological consistency with the adjacent vertebrae is the key $(1,2,7)$. On the other hand, strict morphometric measurement can over-diagnose OVD (8). This may be more a problem for the mid-thoracic spine (24). Wedging from remodeling in osteoarthritis should not be confused with wedging due to osteoporotic fracture (25). Wang et al. suggested that OVD at midthoracic spine level might have been over-diagnosed in many literature reports, particularly for males (24). In their MrOS (USA) follow-up, Freitas et al. also noted that the proportion of both clinically and radiographically diagnosed $\mathrm{VF}$ at mid-thoracic spine level was low (26).

Another issue is how to assess vertebral height loss, should the shortest longitudinal axis of the vertebra to be compared with its posterior height, or with the adjacent vertebrae (9)? To compare the height loss of a vertebra with its adjacent vertebrae will be more reasonable, as the ratio of anterior height to posterior height varies among different vertebral levels, being smallest at mid-thoracic level, being equal to one at L2 level, and this ratio can be $>1$ at lower lumbar vertebrae $(27,28)$. This pattern may also vary among individuals. Additionally, due to the existence of the vertebral posterior 'lipping' ('uncinate process' in some morphometry literatures), the posterior height measure can cause inconsistencies. The examples in this article emphasize the point that we estimate vertebral height loss with adjacent vertebral heights as the reference (Figure 1, Supplementary file, Figures S1-S5). This will of course cause problem when more than one OVD occur simultaneously in one location. For such cases, vertebral height loss estimation can be made by comparing with other normal appearing vertebrae as well as taking consideration of the posterior vertebral height (Figure S3).

This article presents the lateral spine radiograph of 36 cases with OVD (Figures 2-37), one case of thoracic spine osteoarthritis (Figure 38), and one case with vertebra L3 inferior endplate developmental variant (Figure 39). The latter two cases could be mistaken as having OVD. All the cases were Chinese females aged more than 55 years old. To avoid potential controversies, ECF is not annotated in these illustrate cases. Though a vertebra with ECF is not necessarily associated with height loss, ECF usually occurs in the vertebrae with various extents of height loss. The higher extent of vertebral height loss, the more likely ECF exists in a vertebra with osteoporotic deformity, so that when the height loss of a vertebral is $>1 / 3$, ECF can always be detected radiographically $(11,12,14)$. Osteoporotic 


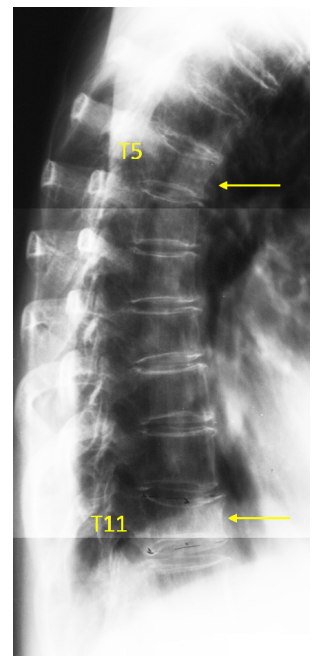

Figure 3 Vertebra T5 and T11 OVD. T5 measured 22\% height loss (GSQ: grade-1, eSQ grading: mild). The reading results was three readers suggesting GSQ grade- 0.5 (eSQ grading: minimal) and two readers suggesting GSQ grade-1 (eSQ grading: mild), one reader suggesting normal due to singular vertebra slightly rotated (fontal review confirmation for this case was not available). Vertebra T11 OVD, estimated 25-33\% height loss (GSQ grade-2, eSQ grading: moderate).

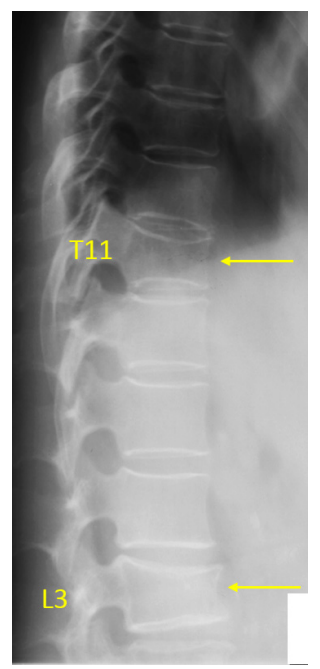

Figure 4 Vertebrae T11 and L3 OVD. T11 estimated 20-25\% height loss (GSQ: grade-1, eSQ grading: mild). Vertebra L3 OVD, estimated 25-33\% height loss (GSQ grade-2, eSQ grading: moderate).

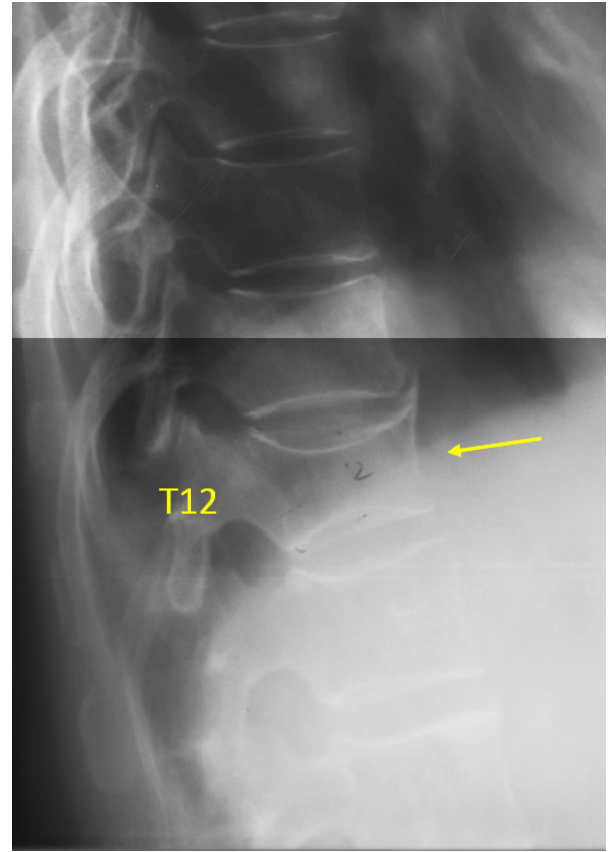

Figure 5 Vertebra T12 OVD, estimated 34-40\% height loss (GSQ grade-2, eSQ grading: moderately-severe).

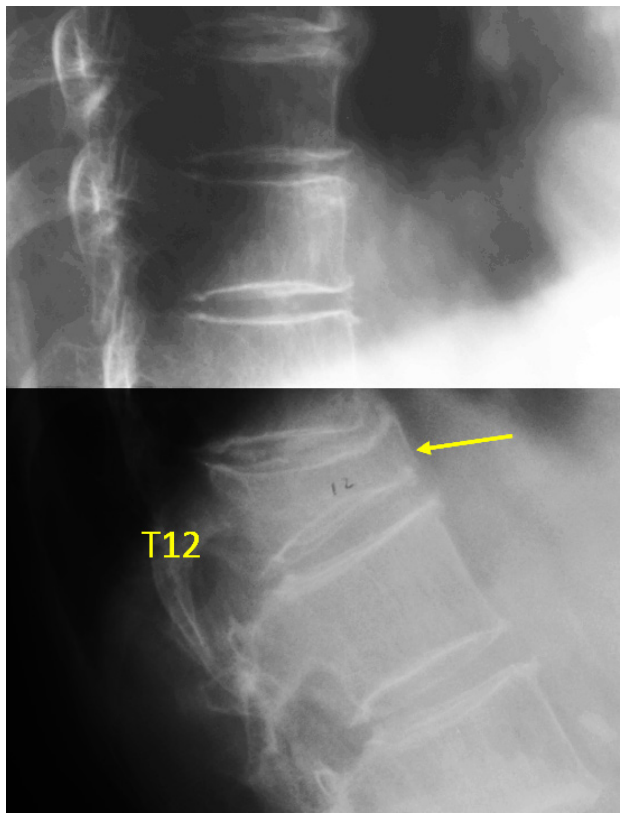

Figure 6 Vertebra T12 OVD, estimated $>67 \%$ height loss (GSQ grade-3, eSQ grading: collapsed). 


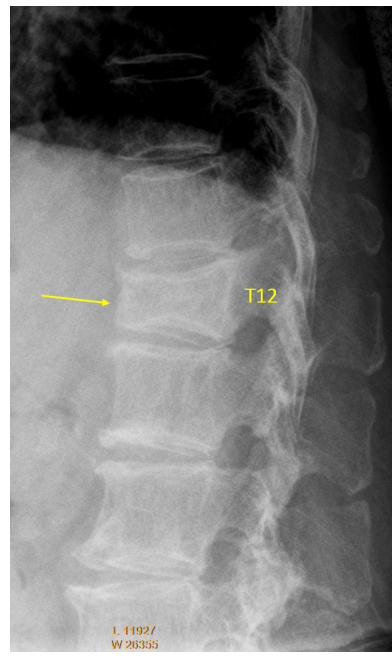

Figure 7 Vertebra T12 OVD, measured 40\% height loss (estimated GSQ grade-2, eSQ grading: moderately-severe; or borderline GSQ grade-2/3, eSQ grading: borderline moderately-severe/ severe).

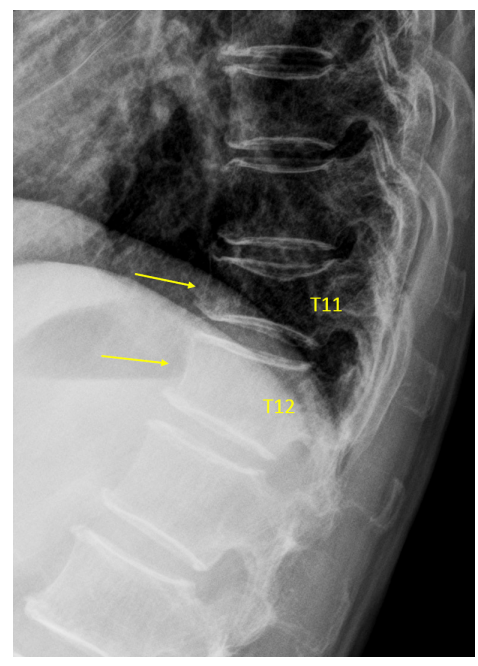

Figure 8 Vertebra T11 and T12 OVD. T11 measured 33\% height loss (GSQ: grade-2, eSQ grading: moderately-severe, or borderline moderate/moderately-severe). T12 estimated GSQ grade-1, eSQ grading: mild.

vertebral height loss is also highly predictive of future ECF development $(11,12)$

This article has several aims. Since original GSQ criteria was primarily explained by text (1), rather than by lots of examples, the examples in this article can serve as teaching material for readers who will use GSQ criteria. The second

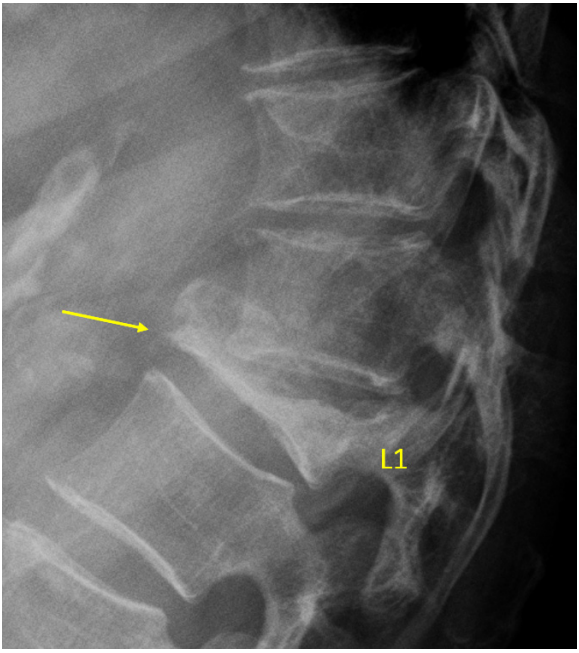

Figure 9 Vertebra L1 OVD, estimated $>67 \%$ vertebral height loss (arrow, GSQ grade-3 and eSQ grading: collapsed).

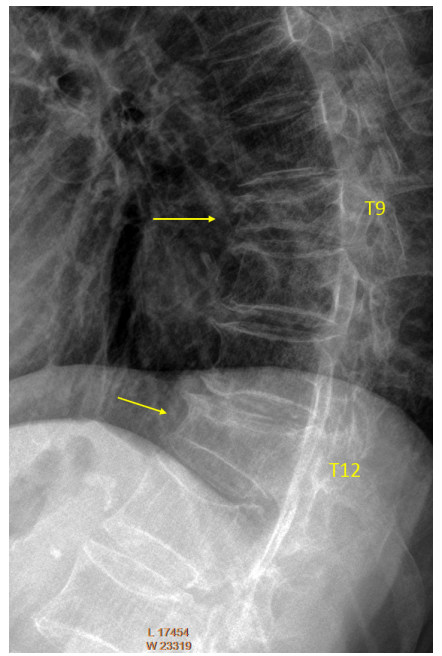

Figure 10 Vertebrae T9 and T12 OVD. T9 GSQ: grade-3, eSQ: severe (2 readers voted for eSQ grading: severe and 4 other readers voted for eSQ grading: collapsed), measured $46 \%$ height loss. T12 estimated GSQ borderline grade-2/3 and eSQ grading: borderline moderately-severe/severe (3 readers voted for eSQ grading: moderately-severe and 3 other readers voted for eSQ grading: severe; measured $39 \%$ height loss). For the possible explanation of the different estimations, please see Figure S6.

aim is to explain our eSQ criteria (Table 1) by examples. Our feeling is that eSQ criteria may be easier to apply than the original SQ criteria in research settings. Though Genant et al. described GSQ grade-0.5 (1), it was rarely used and 


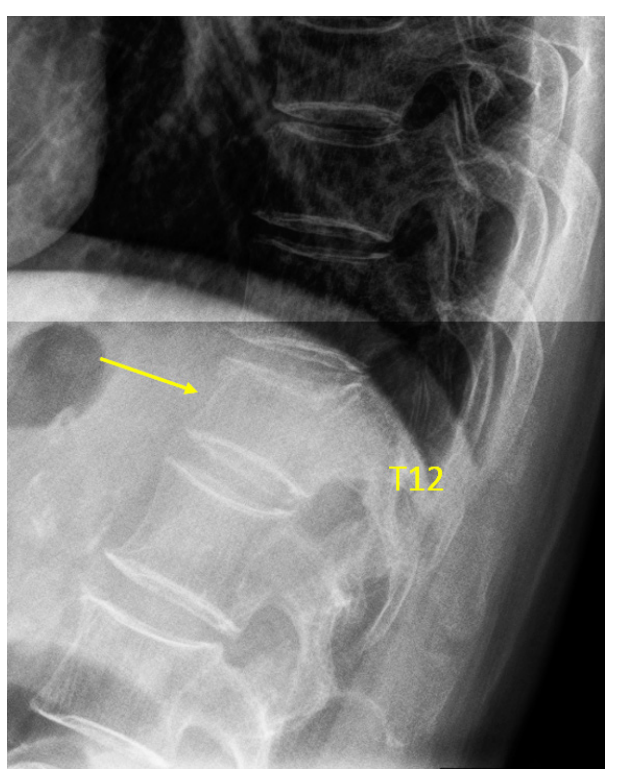

Figure 11 Vertebra T12 OVD, estimated 20-25\% height loss (GSQ grade-1, eSQ grading: mild)

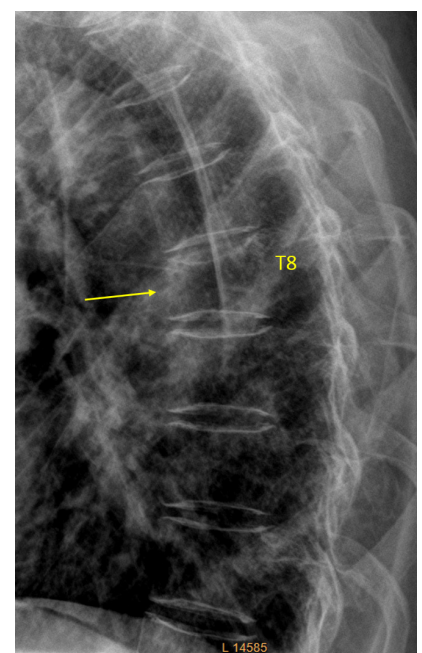

Figure 12 Vertebra T8 OVD. For estimation, two readers voted for GSQ grade-1 and eSQ grading: mild; four readers voted for GSQ grade-2 and eSQ grading: moderate. Measurement suggests approximately $22 \%$ vertebral height loss (GSQ grade-1, eSQ grading: mild).

reported. The introduction of a formal eSQ grade-1 (minimal grade) may solve the problem when a qualitative OVD exists but it does not look like achieving the threshold of $\geq 20 \%$ vertebral height loss. Thus, the reader is not forced to make a 'Yes' or 'No' choice. Another issue is that, for OVDs at the

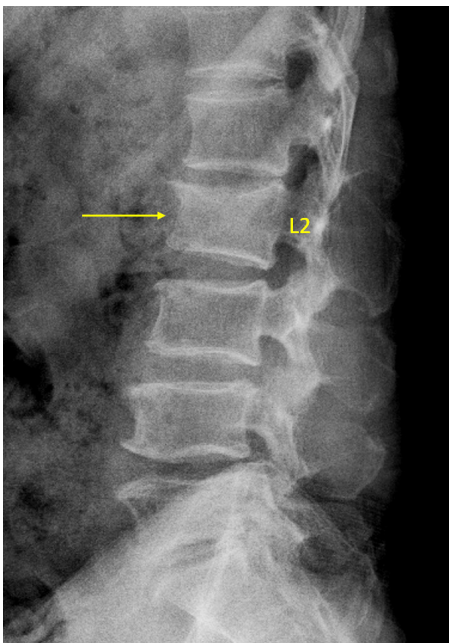

Figure 13 Vertebra L2 OVD, with GSQ grade-1 and eSQ grading: mild (4 readers voted for GSQ grade-1, eSQ grading: mild; 2 readers voted for GSQ grade-2 and eSQ grading: moderate). Based on measurement, the consensus was GSQ grade-1 and eSQ grading: mild.

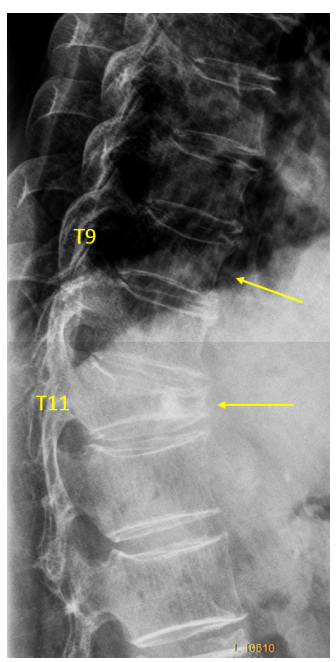

Figure 14 Vertebra T9 and T11 OVD. T9 GSQ grade-0.5 and eSQ grading: minimal (4 reader voted for eSQ grading: minimal; one reader thought it is normal, and while one reader voted for eSQ grading: mild). T9 measured 13\% height loss. T11 estimated GSQ grade-3 and eSQ grading: borderline severe/collapsed.

severe end of GSQ grade-2, it can be ambiguous on should they be assigned to GSQ grade-2 or GSQ grade-3; and introduction of eSQ grade-4 (severely-moderate) may make the assignment more comfortable for the assessors. 


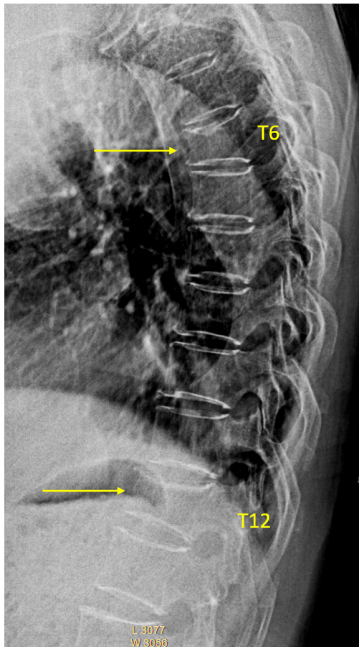

Figure 15 Vertebrae T6 and T12 OVD, both with GSQ grade-2 and eSQ grading: moderate.

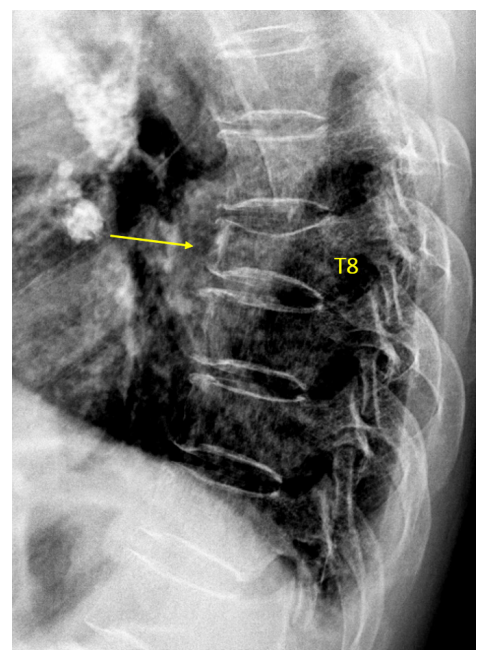

Figure 16 Vertebra T8 OVD, estimated GSQ grade-3 and eSQ grading: severe.

The examples in this article have been read by experts including three of them trained in the original UCSF group. The development of the illustrations followed Delphi principle (29). There were two readers in Hong Kong (YXJ Wáng, N Che-Nordin) who read the images in consensus and counted as one reader. There were additional five primary readers (D Diacinti, W Yu, XG Cheng, MH NogueiraBarbosa, F Ruiz Santiago). To achieve consensus, the images were read three rounds. We tried to solve the initial differences by consensus building and assisted by vertebral

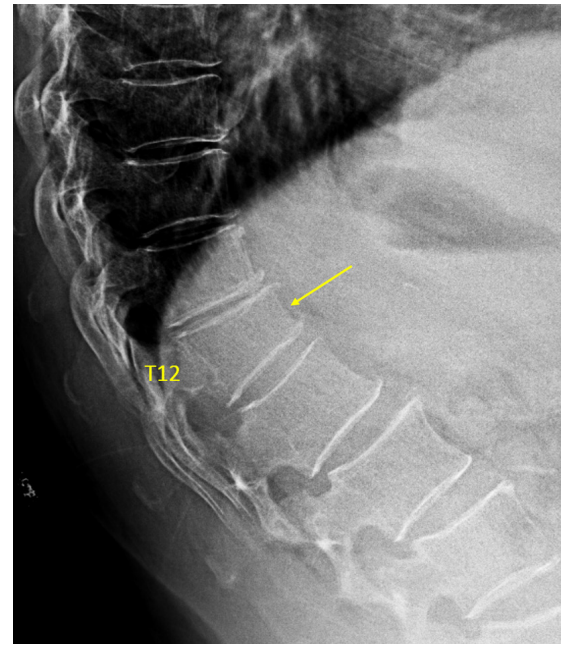

Figure 17 Vertebra T12 OVD, estimated GSQ grade-2 and eSQ grading: moderate.

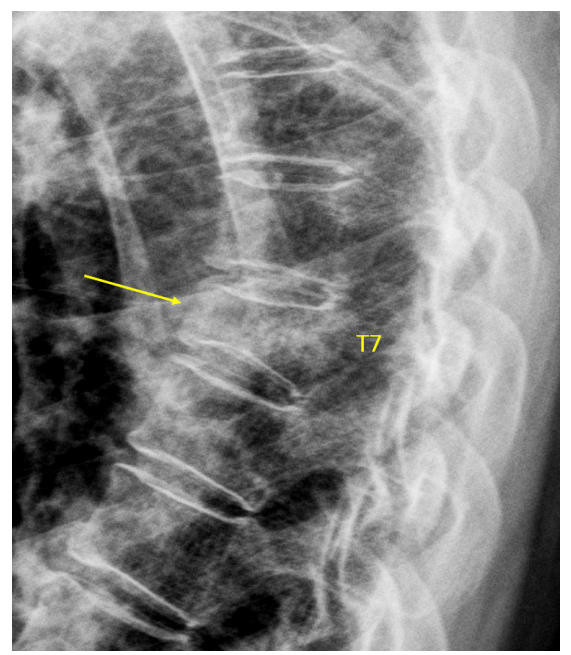

Figure 18 Vertebra T7 OVD, estimated GSQ: grade-2 and eSQ: moderately-severe.

height measurement for borderline cases. Then one more reader (G Guglielmi) read the images and agreed the final results. Note as described by Genant et al. the gradings were primarily estimated (1-3), and there is no ground truth for the grading. A number of disagreements still remain in the end, and disagreements are also presented in this article. It is quite reasonable that disagreements exist for borderline cases.

A general trend was noted that, compared with measured results, visually estimated results tend to overestimate the severity of vertebral height loss. While upper and lower 


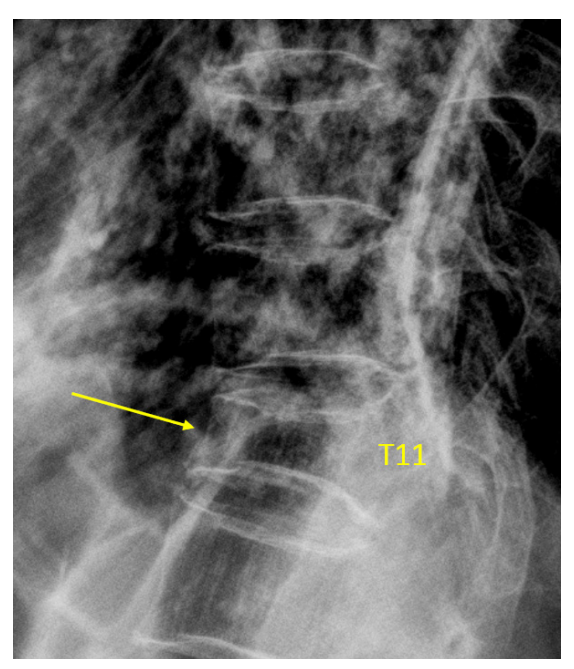

Figure 19 Vertebra T11 OVD, estimated GSQ grade-3 and eSQ grading: severe.

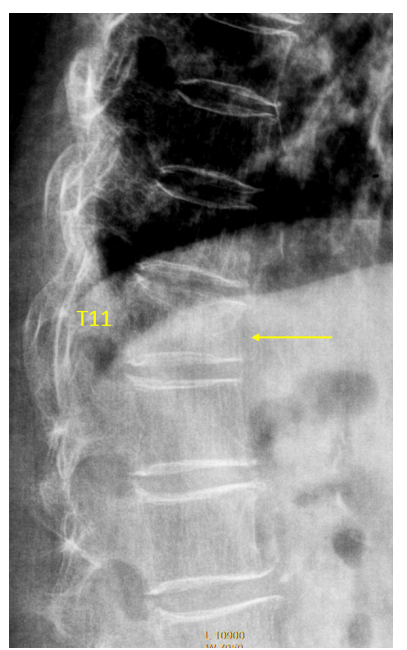

Figure 20 Vertebra T11 OVD, estimated GSQ grade-2 and eSQ grading: moderately-severe.

endplates and their rings may show double-lines or triple/ multiple-lines, it is possible that readers tend to use the most depressed line to visually estimate; while this can induce over-estimation of vertebral height loss (Figure S6). Such inflated estimation would still be acceptable as long as the same standard is used for all readers, and the same standard is applied for baseline and follow-up studies. In such a scenario, readers' performance should be continuously calibrated using an image database, as it has

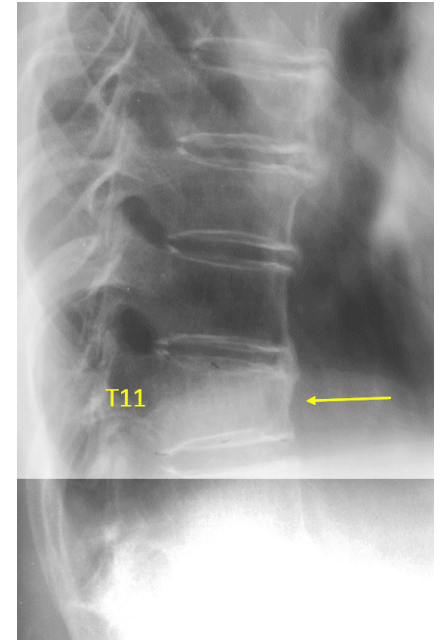

Figure 21 Vertebra T11 OVD, estimated GSQ grade-2 and eSQ grading: moderate.

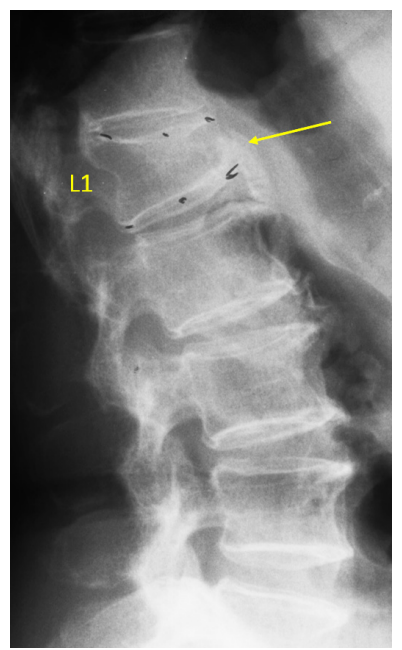

Figure 22 Vertebra L1 OVD, estimated GSQ grade-2 and eSQ grading: moderate.

been known that individual reader's assessment attitude may shift overtime (30). According to our preliminary testing, measurement results with good consistency could be obtained across different readers (YXJ Wáng, D Diacinti, F Ruiz Santiago took part in the testing without face-toface interaction), though this point needs to be further validated. For the future, it is expected that artificial intelligence enabled techniques may improve the speed and consistency of vertebral height loss measurement. 


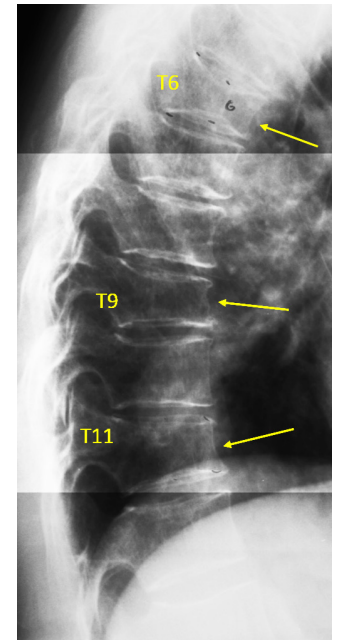

Figure 23 Vertebrae T6, T9, T11 OVD. T6 estimated GSQ grade-2 and eSQ: moderately-severe. T9 estimated GSQ grade-2 and eSQ grading: moderate. T11 estimated GSQ grade-1 and eSQ grading: mild.

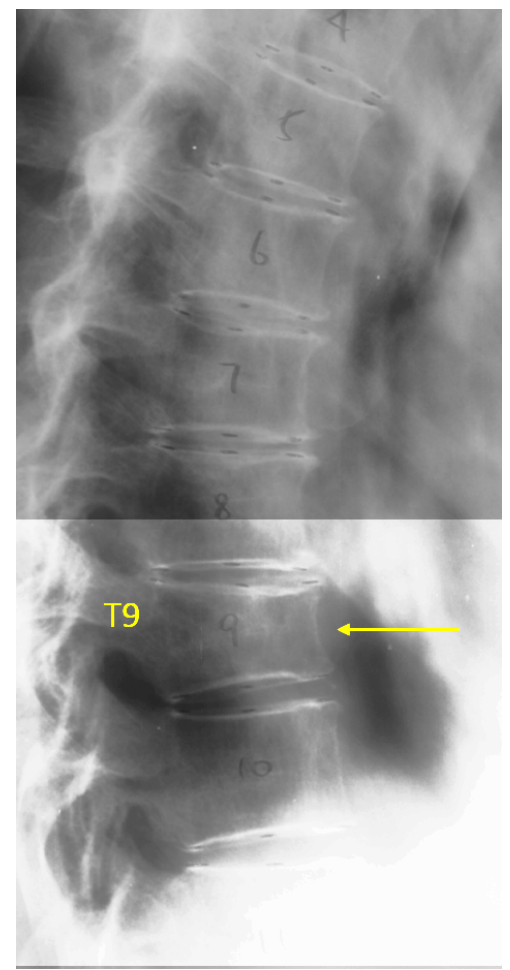

Figure 24 T9 OVD, estimated GSQ grade 1 and eSQ grading: mild.

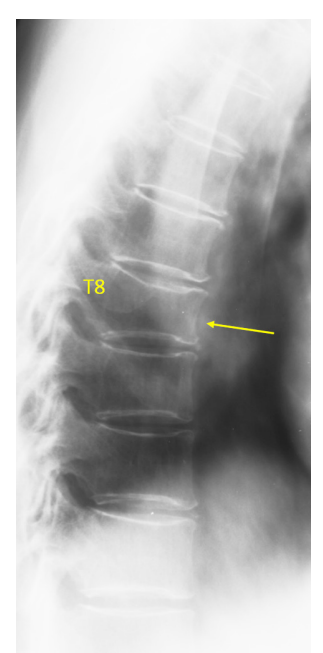

Figure 25 T8 OVD, estimated SQ grade-1 and eSQ grading: mild.

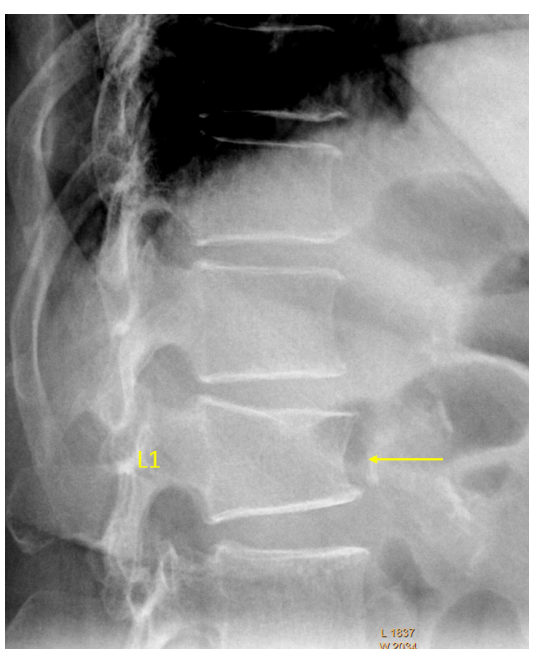

Figure 26 L1 OVD. L1 borderline GSQ grade-1/2 and eSQ grading: mild/moderate (two readers voted for grade-1, while four readers voted for GSQ grade-2 and eSQ grading: moderate). There is an upper endplate Schmorl node. 


\section{Page 10 of 14}

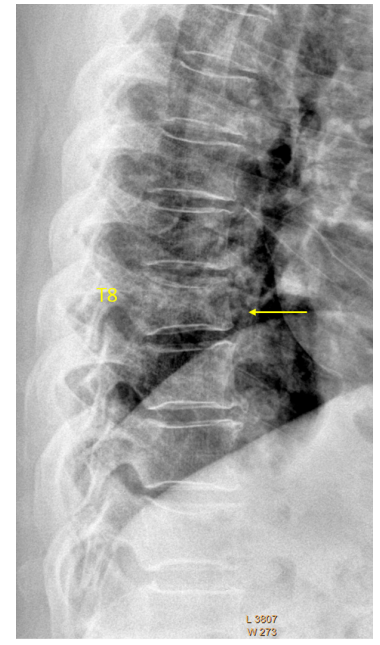

Figure 27 T8 OVD, estimated SQ grade-2 and eSQ grading: moderate.

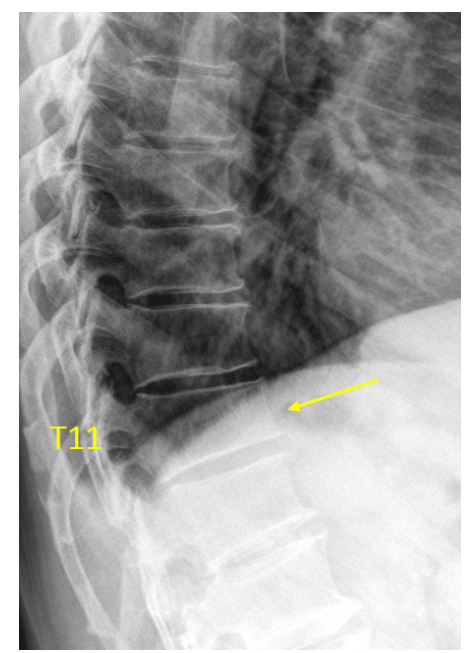

Figure 28 T11 OVD, estimated SQ grade-1 and eSQ grading: mild.

\section{Wáng et al. OVD image database with grading}

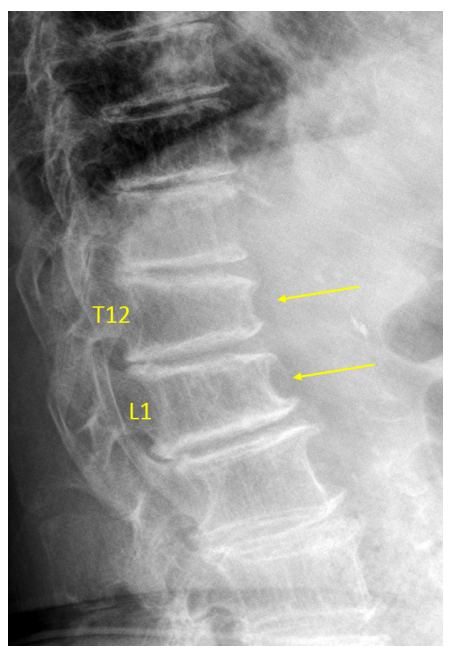

Figure 29 Vertebrae T12 and L1 OVD. T12 estimated SQ grade-2 and eSQ grading: moderate. L1 estimated SQ grade-1 and eSQ grading: mild. These vertebrae co-exist with osteoarthritis.

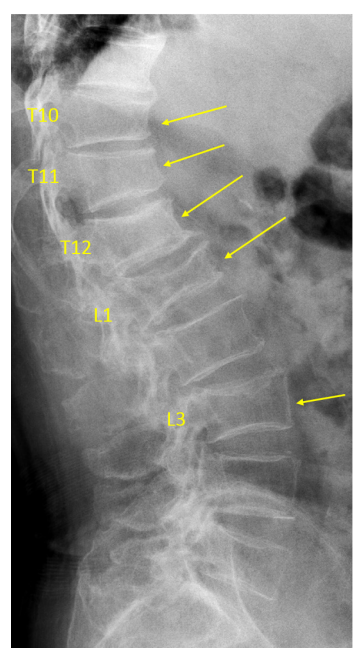

Figure 30 Vertebrae T10, T11, T12, L1, L3 OVD. T10 estimated GSQ grade-2 and eSQ grading: moderate. T11 estimated GSQ grade- 1 and eSQ grading: mild. T12 estimated GSQ grade- 0.5 and eSQ grading: minimal (2 of the 6 readers voted for GSQ grade-1 and eSQ grading: mild). L1 estimated GSQ grade-3 and eSQ grading: severe. L3 GSQ: grade-2 and eSQ grading: moderate. 


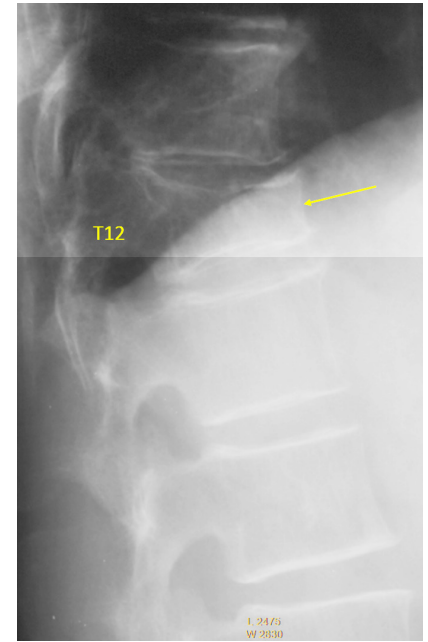

Figure 31 T12 OVD, estimated SQ grade-3 and eSQ severe.

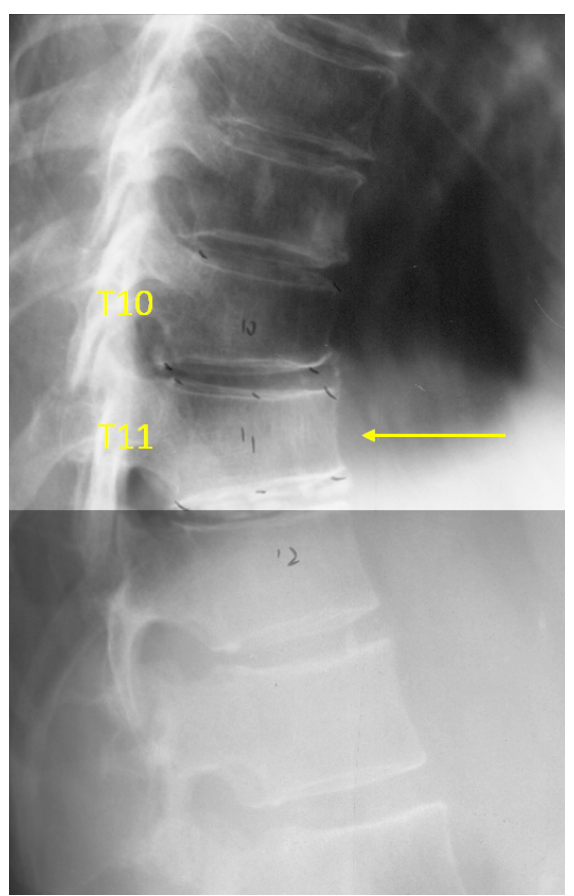

Figure 32 Vertebrae T10 and T11 OVD. T10 estimated SQ grade- 0.5 and eSQ grading: minimal. T11 estimated SQ grade- 1 and $\mathrm{SQ}$ grading: mild.

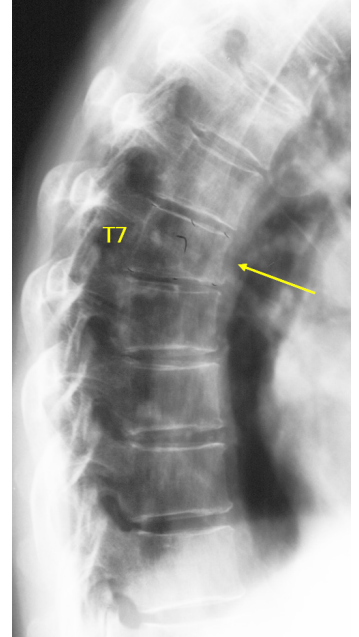

Figure 33 T7 OVD, estimated SQ grade-1 and eSQ grading: mild.

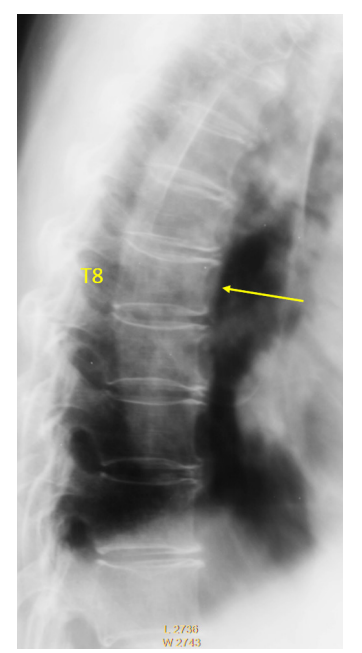

Figure 34 T8 OVD, estimated SQ grade- 0.5 and eSQ grading: minimal. 


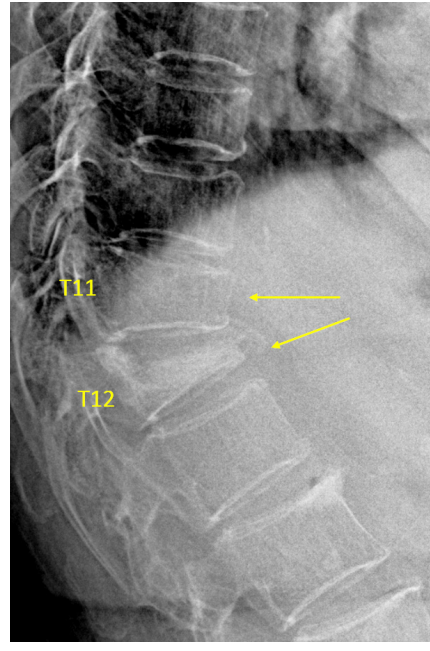

Figure 35 Vertebrae T11 and T12 OVD. T11 estimated GSQ grade-2 and eSQ grading: moderate. T12 estimated SQ grade-3 and $\mathrm{SQ}$ grading: collapsed.

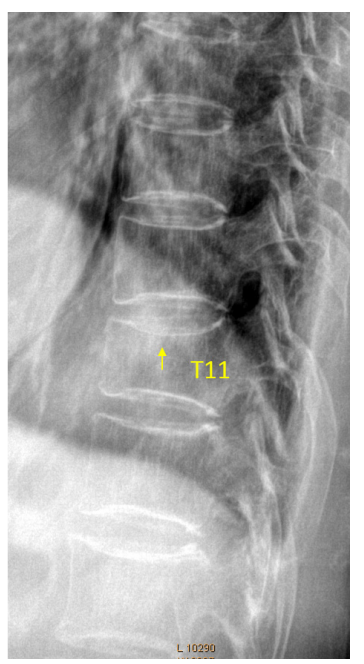

Figure 36 T11 OVD, estimated SQ grade-1 and eSQ grading: mild.

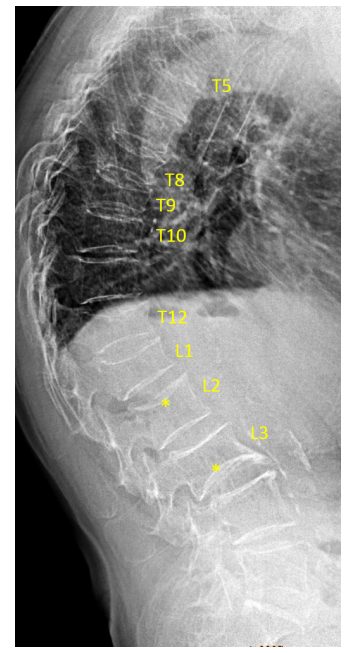

Figure 37 Vertebrae T5, T8, T9, T10, T12, L1, L2 OVD. T5 estimated GSQ grade-3 and eSQ grading: collapsed (5 readers voted for 'collapsed', one reader think it was normal and it was false positive due to lung markings). T8 estimated GSQ grade-3 and eSQ grading: severe. T9 estimated GSQ grade-3 and eSQ grading: severe. T10 estimated GSQ grade-2 and eSQ grading: moderate (for this vertebra, only the regular shape appearing T11 could be used as reference). T12 estimated GSQ grade-2 and eSQ grading: moderately-severe. L1 estimated GSQ grade-2 and eSQ grading: moderately-severe. L2 estimated GSQ grade- 0.5 and eSQ grading: minimal (*: the upper endplate depression). Vertebra L3 inferior endplate developmental variant*, whether there is OVD cannot be determined.

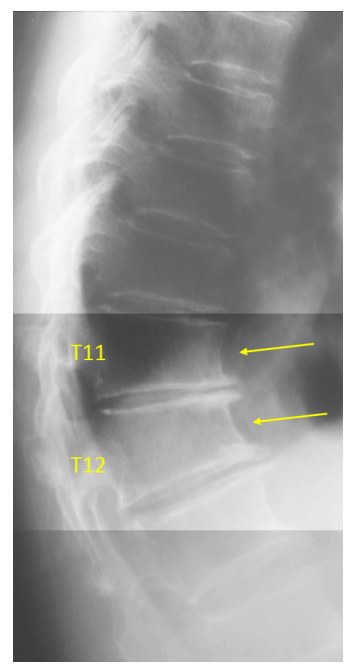

Figure 38 T11 and T12 wedging due to osteoarthritis (see reference 25). Both vertebrae show anterior wedging rather than bi-concave middle height-loss. T11/T12 interverbal disc narrowing and T11/T12/T13 osteophytes are noted. 


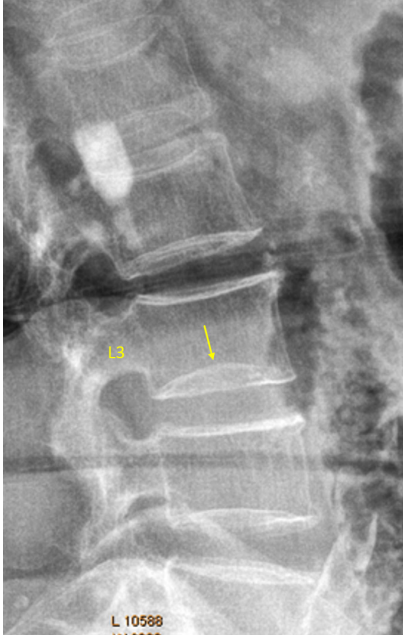

Figure 39 Vertebra L3 inferior endplate developmental variant (possible diagnostic pitfall: endplate fracture).

\section{Acknowledgments}

Funding: This study is partially supported by ITF project of Hong Kong SAR (code: ITS/334/18).

\section{Footnote}

Conflicts of Interest: The authors have no conflicts of interest to declare.

Ethical Statement: The authors are accountable for all aspects of the work in ensuring that questions related to the accuracy or integrity of any part of the work are appropriately investigated and resolved.

Open Access Statement: This is an Open Access article distributed in accordance with the Creative Commons Attribution-NonCommercial-NoDerivs 4.0 International License (CC BY-NC-ND 4.0), which permits the noncommercial replication and distribution of the article with the strict proviso that no changes or edits are made and the original work is properly cited (including links to both the formal publication through the relevant DOI and the license). See: https://creativecommons.org/licenses/by-nc-nd/4.0/.

\section{References}

1. Genant HK, Wu CY, van Kuijk C, et al. Vertebral fracture assessment using a semiquantitative technique. J Bone
Miner Res 1993;8:1137-48.

2. Genant HK, Jergas M. Assessment of prevalent and incident vertebral fractures in osteoporosis research. Osteoporos Int 2003;14:S43-55.

3. Schwartz EN, Steinberg D. Detection of vertebral fractures. Curr Osteoporos Rep 2005;3:126-35.

4. Wáng YX, Santiago RF, Deng M, et al. Identifying osteoporotic vertebral endplate and cortex fractures. Quant Imaging Med Surg 2017;7:555-91.

5. Fechtenbaum J, Briot K, Paternotte S, et al. Difficulties in the diagnosis of vertebral fracture in men: agreement between doctors. Joint Bone Spine 2014;81:169-74.

6. Diacinti D, Vitali C, Gussoni G, et al. Research Department of FADOI. Misdiagnosis of vertebral fractures on local radiographic readings of the multicentre POINT (prevalence of osteoporosis in INTernal medicine) study. Bone 2017;101:230-5.

7. Szulc P. Vertebral fracture: diagnostic difficulties of a major medical problem. J Bone Miner Res 2018;33:553-9.

8. Lentle B, Koromani F, Brown J, et al. The Radiology of Osteoporotic Vertebral Fractures Revisited. J Bone Miner Res 2019;34:409-18.

9. Diacinti D, Guglielmi G. How to define an osteoporotic vertebral fracture? Quant Imaging Med Surg 2019;9:1485-94.

10. Wáng YX. A modified semi-quantitative (mSQ) grading scheme for osteoporotic vertebral fracture in elderly women. Quant Imaging Med Surg 2019;9:146-50.

11. Wáng YX, Che-Nordin N, Deng M, et al. Osteoporotic vertebral deformity with endplate/cortex fracture is associated with higher further vertebral fracture risk: the Ms. OS (Hong Kong) study results. Osteoporos Int 2019;30:897-905.

12. Wáng YX, Che-Nordin N, Deng M, et al. Elderly males with or without existing osteoporotic vertebral fracture have much lower future vertebral fracture risk than elderly females: the MrOS (Hong Kong) year-4 follow-up spine radiograph study. Osteoporos Int 2019;30:2505-14.

13. Du MM, Che-Nordin N, Ye PP, et al. Underreporting characteristics of osteoporotic vertebral compressive fracture in back pain clinic patients of a tertiary hospital in China. J Orthop Translat 2020. doi: 10.1016/ j.jot.2019.10.007.

14. Deng M, Kwok TCY, Leung JCS, et al. All osteoporotically deformed vertebrae with $>34 \%$ height loss have radiographically identifiable endplate/cortex fracture. J Orthop Translat 2018;14:63-6.

15. Jiang G, Eastell R, Barrington NA, et al. Comparison of 
methods for the visual identification of prevalent vertebral fracture in osteoporosis. Osteoporos Int 2004;15:887-96.

16. Lentle BC, Berger C, Probyn L, et al. Comparative analysis of the radiology of osteoporotic vertebral fractures in women and men: cross-sectional and longitudinal observations from the Canadian Multicentre Osteoporosis Study (CaMos). J Bone Miner Res 2018;33:569-79.

17. Yoshida T, Nanba H, Mimatsu K, et al. Treatment of osteoporotic spinal compression fractures. Conservative therapy and its limitation. Clin Calcium 2000;10:53-8.

18. Kim YJ, Chae SU, Kim GD, et al. Radiographic Detection of Osteoporotic Vertebral Fracture without Collapse. J Bone Metab 2013;20:89-94.

19. Deng M, Zeng XJ, He LC, et al. Osteoporotic Vertebral Fracture Prevalence in Elderly Chinese Men and Women: A Comparison of Endplate/Cortex Fracture-Based and Morphometrical Deformity-Based Methods. J Clin Densitom 2019;22:409-19.

20. Wáng YX, Che-Nordin N. Some radiographically 'occult' osteoporotic vertebral fractures can be evidential if we look carefully. Quant Imaging Med Surg 2019;9:1992-5.

21. Wáng YX, Deng M, He LC, et al. Osteoporotic vertebral endplate and cortex fractures: a pictorial review. J Orthop Translat 2018;15:35-49.

22. Wáng YX, Che-Nordin N. Informed communication with study subjects of radiographically detected osteoporotic vertebral deformity. Quant Imaging Med Surg 2018;8:876-80.

23. Ferrar L, Jiang G, Adams J, et al. Identification of vertebral fractures: an update. Osteoporos Int 2005;16:717-28.

24. Wáng YX, Wang XR, Che-Nordin N, et al. On the possibility of over-diagnosis of osteoporotic vertebral fracture at mid-thoracic level. J Thorac Dis 2019;11:5708-11.

25. Abdel-Hamid Osman A, Bassiouni H, Koutri R, et al. Aging of the thoracic spine: distinction between wedging in osteoarthritis and fracture in osteoporosis--a crosssectional and longitudinal study. Bone 1994;15:437-42.

26. Freitas SS, Barrett-Connor E, Ensrud KE, et al. Osteoporotic Fractures in Men (MrOS) Research Group. Rate and circumstances of clinical vertebral fractures in older men. Osteoporos Int 2008;19:615-23.

27. Lauridsen KN, De Carvalho A, Andersen AH. Degree of vertebral wedging of the dorso-lumbar spine. Acta Radiol Diagn (Stockh) 1984;25:29-32.

28. Matsumoto M, Okada E, Kaneko Y, et al. Wedging of vertebral bodies at the thoracolumbar junction in asymptomatic healthy subjects on magnetic resonance imaging. Surg Radiol Anat 2011;33:223-8.

29. McMillan SS, King M, Tully MP. How to use the nominal group and Delphi techniques. Int J Clin Pharm 2016;38:655-62.

30. Wang YX, Kuribayashi H, Wågberg M, et al. Gradient echo MRI characterization of development of atherosclerosis in the abdominal aorta in Watanabe Heritable Hyperlipidemic rabbits. Cardiovasc Intervent Radiol 2006;29:605-12.
Cite this article as: Wáng YXJ, Diacinti D, Yu W, Cheng XG, Nogueira-Barbosa MH, Che-Nordin N, Guglielmi G, Ruiz Santiago F. Semi-quantitative grading and extended semiquantitative grading for osteoporotic vertebral deformity: a radiographic image database for education and calibration. Ann Transl Med 2020;8(6):398. doi: 10.21037/atm.2020.02.23 
How to performance quantitative measurement for vertebral height does not have a consensus yet. Varying parallax distortion of vertebral body borders can cause problems for the placement of the points (cursors) used for quantification. The placement of these points (cursors) remains a subjective "reading" of the radiograph, and inevitable variation in patient positioning results in additional variation for point placement. In spine levels at a distance from the center of the X-ray beam, nonorthogonal projection is the rule rather than the exception. There can also be confusion in the interpretation of radiographic line representing central endplate, with the peripheral vertebral ring sometimes mistaken for the central endplate. On a lateral projection, the superior (or inferior) surface of the normal vertebra exhibits two lines; one line represents one side of the vertebral ring, and the second line represents the central endplate superimposed on the opposite vertebral ring. It is likely that the centre of the endplate within the vertebral ring is the weakest area, this will be the primary site of osteoporotic deformity. Ideally, in concave osteoporotic fractures, the line representing the centre of endplate is measured upon. However, identification of the line representing the endplate is not always easy and reliable. To simplify the procedure and improve consistency, we use the initial description by Genant et al. (1) (Figure S1). As the identification of the line representing depressed endplate can be difficult, this approximate approach may simply further artificial intelligence technology development procedures.
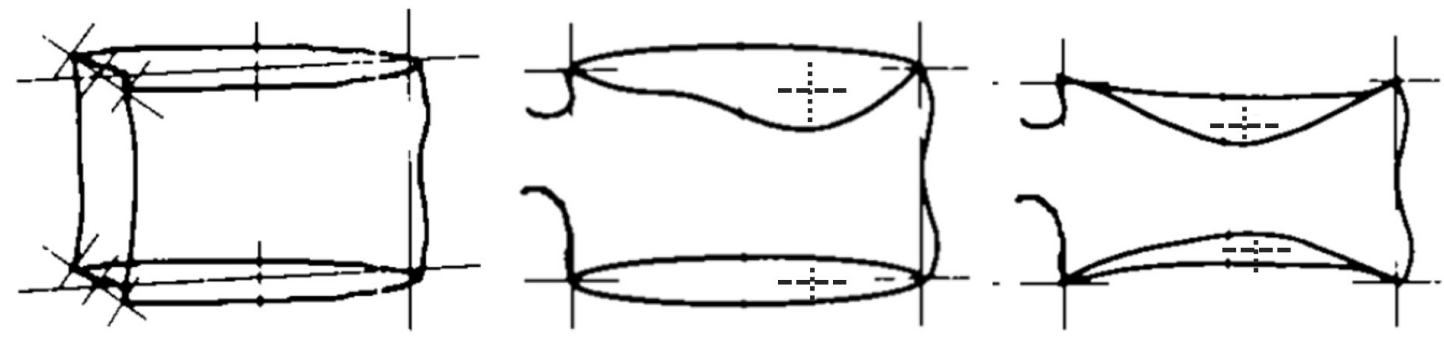

Figure S1 Examples of placement of the points used for quantitative measurement [modified from Genant et al. (1)]. Contrasting the 6 points method, we take the longitudinal axis with the most severe height loss for measurement.
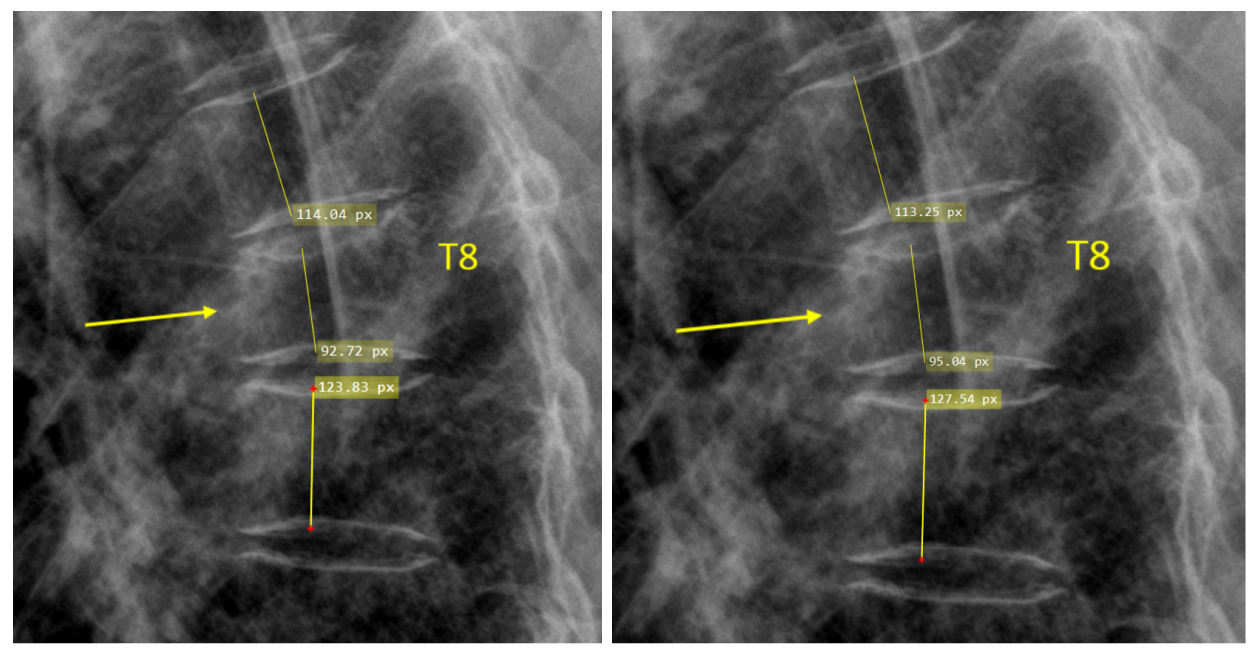

Figure S2 Measurement of T8 OVD height loss, the reference was the mean of T7 and T9 (measure twice and take the mean). 

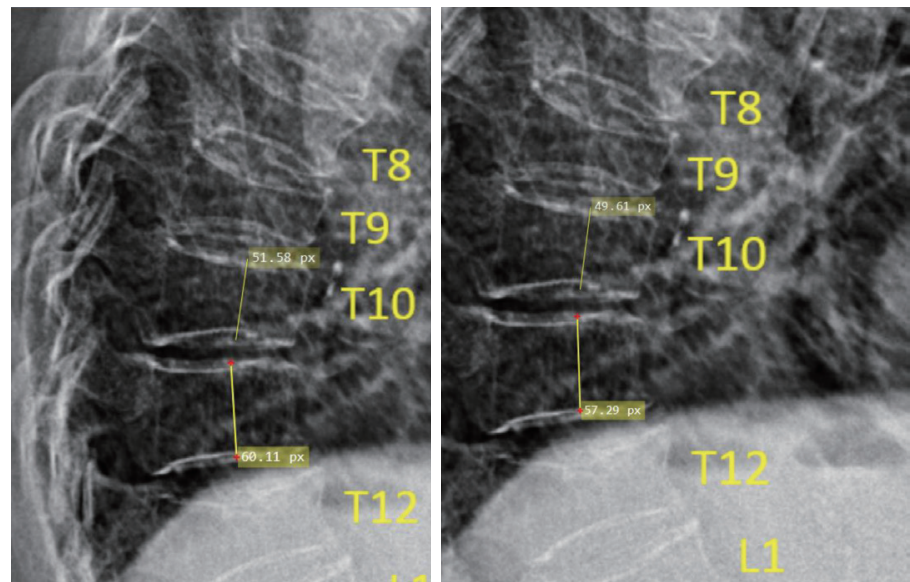

Figure S3 Measurement of T10 OVD height loss, the reference was only T11 as both T8 and T9 have OVD as well (measure twice and take the mean).
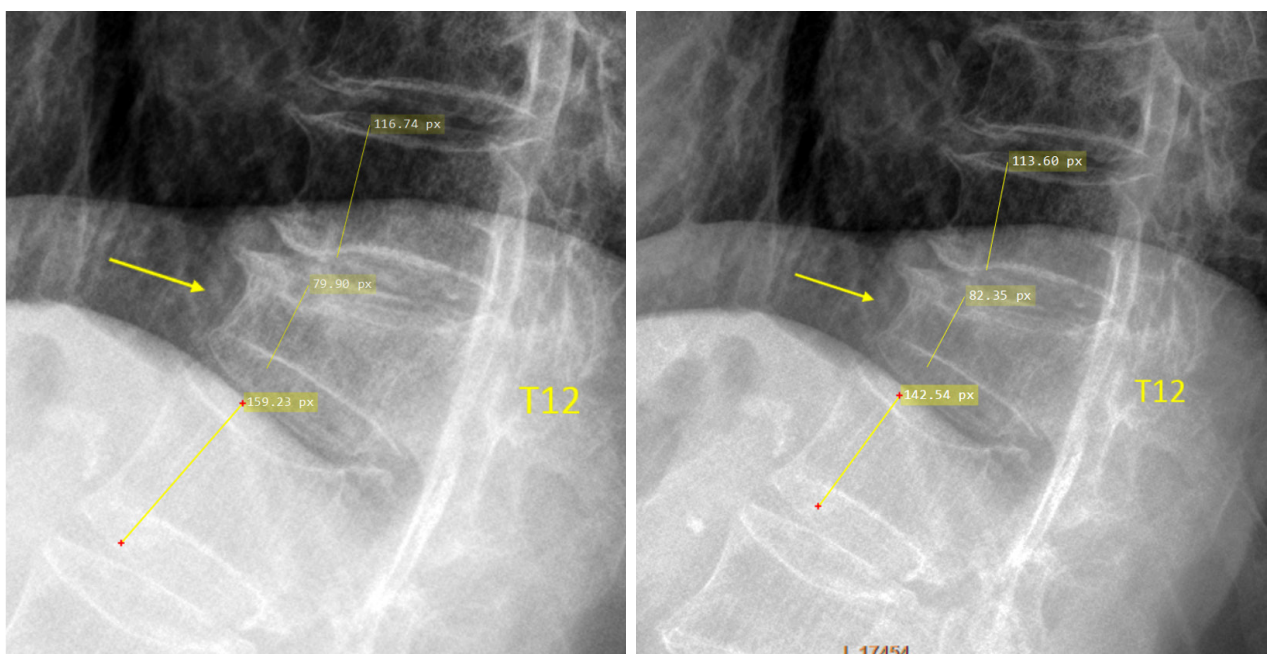

Figure S4 Measurement of T12 OVD height loss, the reference was the mean of T11 and L1 (measure twice and take the mean). 


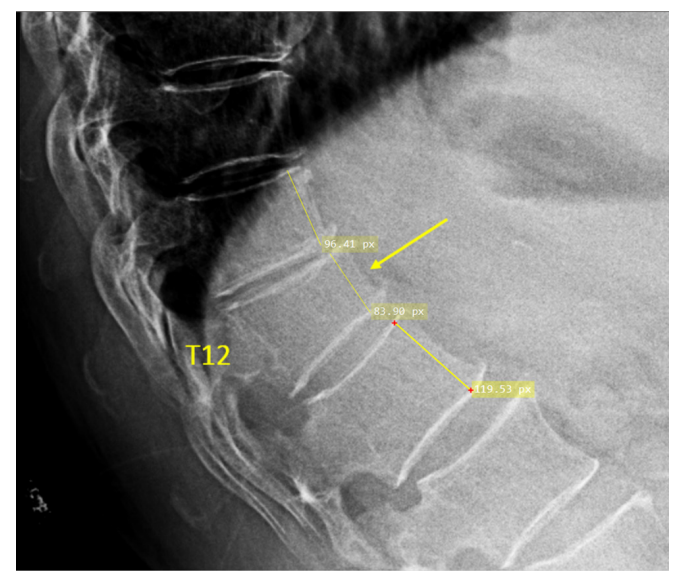

Figure S5 Measurement of T12 OVD height loss, the reference was the mean of T11 and L1.
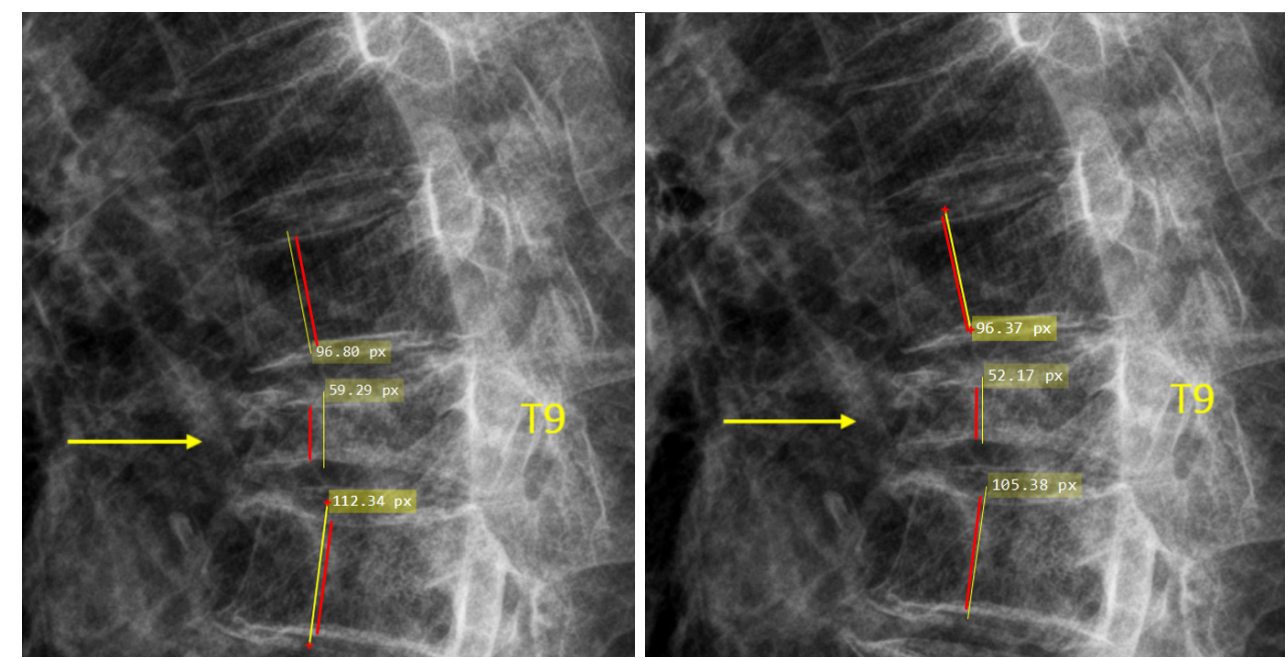

Figure S6 To measure the height loss of T9, the height measured by the yellow line of T9 was compared with the mean height of T8 and T10 (also measured by the yellow line). However, for visual estimation, a tendency could occur that the readers take the heights denoted by red lines to estimate, which could lead to overestimation of the height loss. 